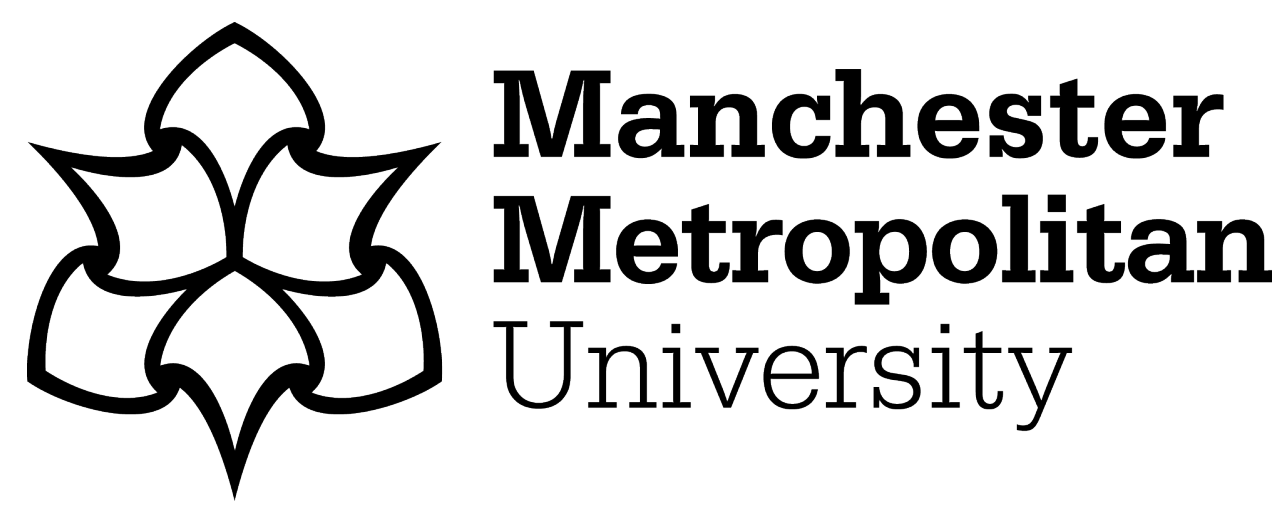

Molla, T, Harvey, A and Sellar, S ORCID logoORCID: https://orcid.org/00000002-2840-5021 (2018) Access to languages other than English in Australian universities: an educational pipeline of privilege. Higher Education Research and Development, 38 (2). pp. 307-323. ISSN 0729-4360

Downloaded from: https://e-space.mmu.ac.uk/623400/

Version: Accepted Version

Publisher: Taylor \& Francis

DOI: https://doi.org/10.1080/07294360.2018.1522620

Please cite the published version 


\title{
Access to languages other than English in Australian universities: an educational pipeline of privilege
}

\author{
Tebeje Molla (D) ${ }^{a}$, Andrew Harvey (1) ${ }^{b}$ and Sam Sellar (1) ${ }^{c}$ \\ ${ }^{a}$ School of Education, Deakin University, Geelong, Australia; ${ }^{b}$ Centre for Higher Education Equity and Diversity \\ Research, La Trobe University, Melbourne, Australia; ${ }^{\mathrm{C}}$ Reader in Education Studies, Manchester Metropolitan \\ University, Manchester, UK
}

\begin{abstract}
This article explores factors contributing to unequal patterns of access to languages other than English (LOTE) in Australian universities. A critical analysis of qualitative and quantitative data generated through interviews, surveys and document analysis reveals that underrepresentation in LOTE courses in Australian universities is attributable to: (a) unequal access to LOTE learning areas at the school level; (b) low tertiary entrance scores that do not grant access to elite universities that offer broad LOTE course options; (c) differential prior international learning experiences that inform dispositions towards intercultural competence, including proficiency in LOTE; and (d) limited provision of LOTE courses in regional university campuses. We conclude that access to foreign language courses in Australian universities is not equitable, and in the context of globalisation opportunities, this poses a risk of reproducing social disadvantage alongside other structural factors such as socio-economic status and regional background.
\end{abstract}

\section{Introduction}

Multilingualism and intercultural capability are increasingly important attributes of global citizenship. A person's ability to live and work in different parts of the world partly depends on his or her language skills and the competence to interact with other cultures. The phenomenon of globalisation favours agents with strong multilingual capability and intercultural awareness (Scholte, 2005). In this context, international organisations such as the United Nations Educational, Scientific and Cultural Organization (UNESCO), the Organization for Economic Cooperation and Development (OECD), and the European Union (EU) have called for member states to commit to supporting foreign language learning. For example, part of Article 19 of the 1995 UNESCO Declaration and Integrated Framework of Action on Education for Peace, Human Rights and Democracy states that 'learning foreign languages offers a means of gaining a deeper understanding of other cultures, which can serve as a basis for building better understanding between communities and between nations' (UNESCO, 1995). Harvard University linguist Bruno della Chiesa argues that learning a language is more than just a matter of acquisition - it involves 
gaining knowledge, know-how and interpersonal skills, and is instrumental in redefining people's cultural identities and promoting social integration (della Chiesa, 2010). The Australian Chamber of Commerce and Industry has also expressed optimism about the economic value of learning languages other than English (LOTE): 'To effectively participate in a globalised world there should be the compulsory learning of a foreign language from 7 years of age or earlier' (quoted in Group of Eight, 2007, p. 2).

Despite these entreaties, participation in LOTE learning has been in decline in many Anglophone countries. According to a report by Universities UK (2017), between 2005/ 06 and 2015/16, the number of students enrolled in language courses in UK higher education dropped by $20.6 \%$ (136,460-108,355). The proportion of US higher education students enrolled in languages declined from 9.1\% in 2006 to $8.1 \%$ in 2013 (Goldberg, Looney, \& Lusin, 2015). In Canada, the number of universities that require undergraduates to undertake a second language for degree completion has dropped considerably from $35 \%$ in 1991 to $9 \%$ in 2006 (AUCC, 2009, p. 11). In Australia, the number of foreign languages offered in universities has also dropped significantly (Group of Eight, 2007; Lo Bianco, 2016). Many universities have closed language programmes (Anderson, 2013; Kinoshita \& Zhang, 2013) and participation in languages study has also fallen dramatically. This decline in foreign language enrolments has contributed to 'the rise of the monoglots' (monolingual graduates) who may find it difficult to effectively engage in multilingual global labour markets (Charbonneau, 2008).

Inequality in access to LOTE in Australian universities is an under-researched topic. Previous student equity research published in Higher Education Research \& Development (e.g., Habel, 2012; McNamee \& Maxwell, 1993; O’Shea, Lysaght, Roberts, \& Harwood, 2016; Reid, Barker, \& Murphy, 1995; Thomas, 2014; Willems, 2010) focused on participation and learning experiences in general. Little is known about the scope and trends of inequality in access to language studies. To address this knowledge gap, in this article, we analyse factors of inequalities in access to LOTE courses in Australian universities. Higher education is increasingly expected to support students to develop global competencies that lead to improved economic outcomes (e.g., graduate employability) and intercultural knowledge, and LOTE is central to the role of education in producing global citizens, which is one of the UN Sustainable Development Goals (4.7). We argue that despite this importance, the provision of LOTE is declining in Australian universities and is marked by unequal patterns of participation. Specifically, we identify four factors of inequality in LOTE opportunities in Australian universities: (a) unequal access to LOTE learning at a school level; (b) low Australian Tertiary Admission Rank (ATAR) results and unequal access to leading LOTE providers; (c) differential prior international learning experience; and (d) limited LOTE course options in regional university campuses. We conclude that these patterns, themselves caused by limitations among both supply of and demand for language learning opportunities, will need to be addressed to avoid universities exacerbating inequities as they strive to develop global citizens.

The article proceeds in five main sections. The first section briefly presents the methods and scope of the study. The second section outlines the provision of LOTE in Australian universities. The third section examines how low socio-economic status (SES) and regional background limit students' ability to access LOTE courses in universities. The fourth section calls for a broader view of the value of languages study and the conclusion outlines some policy implications. 


\section{Methods and scope of the study}

This article reports on a project that sought to: (a) map the geo-demographics of outbound mobility (e.g., exchange) and foreign language student cohorts; (b) identify barriers to participation for low socio-economic status and regional students; and (c) identify institutional programmes that facilitate global experiences for these students (Harvey et al., 2016). The project employed a multi-stage mixed methods approach, blending quantitative and qualitative data (Creswell, 2014).

This research design enabled us to capture the state of LOTE study and outbound student mobility in Australia and to better understand the research problem. Data were collected in relation to participation in LOTE courses and outbound mobility programmes, university globalisation strategies, overseas study (OS) help loans, and passport applications. Following a critical review of the current literature to map trends in languages study and student mobility in HE nationally and internationally, we collected qualitative and quantitative data. We conducted two surveys of staff within Australian public universities. The surveys were designed to determine the policies and strategies universities currently have in place to support under-represented students, particularly low SES and regional students, to: (1) study a foreign language, and; (2) participate in outbound mobility programmes. Invitations to complete the online survey were emailed to senior staff with responsibility for language and outbound mobility programmes at all 37 Australian public universities. A total of 21 universities responded to the language survey. Removing the four universities who do not offer language study, this represents a $64 \%$ response rate. A desktop review of the strategic plans, graduate attribute statements and scholarships and bursaries programmes at all Australian public universities was also conducted to complement these surveys. We also requested customised data from the Australian Government Department of Education and Training. The data covered undergraduate students who had studied at least one foreign language unit in the last four years.

Included alongside the survey data were internal institutional enrolment data from the planning units of the two universities in which the project was based at. To gather information on geo-demographic characteristics of students who have participated in LOTE studies, we used data from a recent survey undertaken by one of the participating universities. Other student enrolment data has also been generated from the Australian Department of Education and Training 'uCube' data website. ${ }^{1}$ Data on foreign language study was collected by identifying students who had studied at least one unit or subject which had a detailed field of education related to foreign language study in the last four years. Once students participating within both of these activities were identified, we were able to match this data to enrolment records and cross tabulate language study against two socio-demographic variables, namely SES and geographic location (remoteness). Finally, we interviewed domestic students who participated in foreign language study. A total of 15 interviews were conducted across the two universities. Interviews were conducted with students of diverse socio-cultural backgrounds from an Innovative Research University (IRU) multi-campus university, and a university from the Group of Eight universities (Go8). The rationale for this component of the study was to explore more deeply the experiences of students participating in language studies.

At the analysis stage, we first identified students who had studied at least one unit or subject which had a detailed field of education related to foreign language study in the 
last four years. Once students participating within both of these activities were identified, we were able to match this data to enrolment records and cross tabulate language study against two socio-demographic variables, namely SES and geographic location (remoteness).

\section{LOTE provision in Australian universities}

In Australia, learning languages other than English is seen as important for economic and cultural reasons, as well as for regional cooperation and security. This is a significant shift from a traditional humanist view of language studies started in the second half of the 1980s (Bowden, Starrs, \& Quinn, 1989). As in other Anglo-phone countries (e.g., see Goldberg et al., 2015; AUCC, 2014), and in light of broad national strategic plans, Australian universities have identified global competence as a critical graduate attribute. Global competence can be defined as 'having an open mind while actively seeking to understand cultural norms and expectations of others, leveraging this gained knowledge to interact, communicate and work effectively outside one's environment' (Hunter, 2004, p. 1). Foreign language proficiency is one of the central elements of global competence and universities offer a range of languages other than English (LOTE) courses. Most universities now have aspirations to be 'globally engaged,' 'globally networked' or an 'international institution'.

Recent empirical work on language provision in Australian universities has shown that, while the range of languages being taught at Australian universities has grown (from 32 in 2006, to 45 in 2011), there are large gaps in provision between universities (Dunne \& Pavlyshyn, 2012). The university survey and globalisation strategy reviews that we conducted as part of our research reveal that LOTE study was much less tangibly recognised as a globalisation opportunity for students. While the majority of universities specified increasing outbound mobility opportunities in their strategic documents, only four universities recognised language study as an element of internationalisation or globalisation strategies. Furthermore, these references were often minimal in the sense that the intention was narrowly defined as promoting linguistic diversity. The Australian national data shows that total numbers of students studying a foreign language remained largely unchanged in recent years. However, between 2011 and 2014, the proportion of domestic undergraduate students studying at least one foreign language unit declined from $4.2 \%$ to $3.8 \%$. Overall, Southern European languages (which include French, Italian and Spanish) are the most popular field of education in terms of foreign language study, with $43.8 \%$ of all foreign language unit enrolments. Eastern Asian languages (including Chinese, Japanese and Korean) are the second most popular with $36.7 \%$ of all language unit enrolments.

At school level in Australia, languages other than English have been organised in most instances into the following three groupings: strategic languages (Chinese, Japanese, Indonesian, Korean, Arabic); academic languages (Latin, Ancient Greek, French, German, Spanish); and community languages (Italian, Modern Greek, Vietnamese, Cantonese, Auslan, etc.). In 2011, there were eighteen strategic, fourteen academic, and three community languages offered in Australian universities (Dunne \& Pavlyshyn, 2012). At university level, the most common languages offered at the 21 respondents' universities were French, Japanese and Mandarin, with $71 \%$ of universities offering these languages. Italian was offered at $68 \%$ of universities. German, Spanish and Indonesian were offered at, respectively, $57 \%, 52 \%$ and $48 \%$ of universities. The most common 'other' language listed was 
Modern Greek, which was offered by $23 \%$ of the universities. For the two universities that led this project, French is the most commonly studied language, with Spanish and Japanese the next most commonly studied languages.

It is worth noting that Australia is no exception in prioritising strategic and community languages. In light of globalisation, governments select strategically important foreign languages on the basis of geo-political and security interests, economic relations, and historical heritage. In the U.S., as a reflection of the country's increased economic and security interest in Asia, the proportion of students enrolled in Chinese and Arabic languages grew from $2.4 \%(34,153)$ and $0.8 \%(10,584)$ in 2002 to $3.9 \%(61,055)$ and $2.1 \%(32,286)$ in 2013 (Goldberg et al., 2015). In the UK, Chinese and other Asian languages are of great interest, reflecting current political and economic strategies. In Scotland, although the government leaves the selection of specific languages to be offered as second language (L2) and third language (L3) to local authorities and schools, it suggested that priority should be given to languages of nearest European countries such as French, German, Italian and Spanish (Scottish Government, 2012). In New Zealand, because of the country's geographic proximity and close socio-economic relations with the peoples of the Pacific region, Pasifika languages have prominence in language education programmes. ${ }^{2}$ Even so, a recent survey shows that nearly $50 \%$ of the respondents preferred Chinese as the most important foreign language (Asia New Zealand Foundation, 2015). For a range of reasons, including 'educational provincialism', geographical proximity to the U.S. and preferences to heritage languages, Canada has not effectively engaged in the provision of strategically important foreign languages. Most importantly, 'a China knowledge deficit' is prominent (Dunch, 2012). Fewer than 20 Canadian higher education institutions offer Chinese language as an undergraduate programme or as a course toward some credits (Dunch, 2012).

Within Australia, the diversity of LOTE courses and the intensity of participation in LOTE vary by university groupings. Australian university groups include the eight most selective, metropolitan based universities (Group of Eight, Go8); exclusively regional universities (Regional Universities Network, RUN); technology-focused universities (Australian Technology Network, ATN); and a group of relatively new institutions known as the Innovative Research Universities (IRU). There are also a small number of non-aligned universities. Over $58 \%$ of all foreign language study is conducted at the Group of Eight universities, with unaligned universities coming a distant second with $17 \%$ of all foreign language enrolments. We were able to estimate the foreign language participation rate for each grouping by calculating it as a proportion of overall undergraduate enrolments. The results are displayed in Figure 1. We found that almost 10\% of all students at Go8 institutions were studying a foreign language, which is more than three times higher than the participation rates reported by the IRU grouping, who reported the second highest foreign language study participation rate. The Regional Universities Network reported the lowest foreign language participation rate with $1.8 \%$ of undergraduate domestic enrolments.

\section{Inequality in access to LOTE}

In many Anglophone countries, inequality in access to LOTE is associated with social disadvantage. A recent Language Trends Survey in England shows a marked social imbalance in foreign language admission rates in the English higher education system. The report 


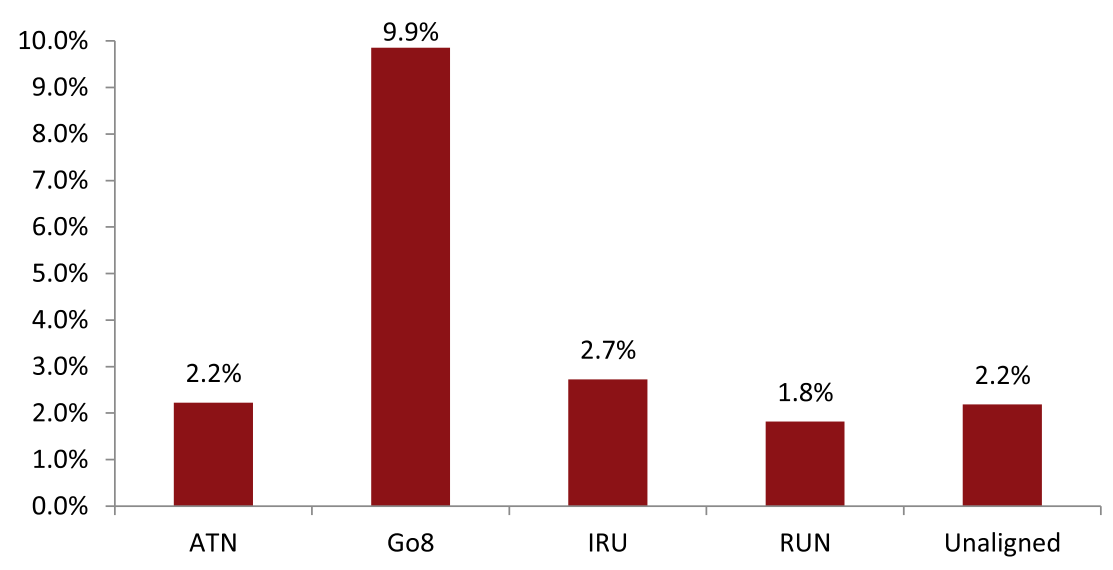

Figure 1. 2014 Participation rates in LOTE courses by intuitional grouping. Source: Commonwealth Department of Education and Training customised data request. Overall enrolment numbers by institutional grouping sourced from the National Centre for Student Equity in Higher Education (NCSEHE) (Koshy, 2014).

reveals that there is 'very strong evidence which shows that language learning is associated with privilege and higher socioeconomic status, and that language courses tend to be concentrated in the older universities' (Tinsley, 2013, p. 132). The 2012 version of this Language Trends Survey stated:

Schools with lower levels of social deprivation, measured by proportions of pupils eligible for free school meals, are more likely to have languages as a compulsory subject in KS4 [Key Stage 4, i.e., Year 10-11] than schools with higher levels of social deprivation. (Tinsley \& Han, 2012, p. 15)

For example, in 2010, about $79 \%$ of students in independent schools took a foreign language in General Certificate of Secondary Education (GCSE), while the figure dropped to $40 \%$ for comprehensive schools (Tinsley \& Han, 2012). In England, a Cambridge Assessment survey revealed that students from grammar and independent schools 'were generally at least twice as likely to have chosen a foreign language as one of their AS (Advanced Subsidiary) ${ }^{3}$ or A2 (Advanced Year Two) level subjects than pupils in any other type of school in the survey' (Cambridge Assessment, 2009, para.8). Similarly, in Wales, the overall proportion of students who took a GCSE in a foreign language dropped from $55 \%$ in 1995 to $22 \%$ in 2013, and the participation rate further declined into single figures in socio-economically disadvantaged schools (Board \& Tinsley, 2015). Considering the potential socio-economic returns of multilingualism highlighted above, access to language education is a matter of social inclusion. As Piller (2014) observes, 'Linguistic diversity is highly relevant to social inclusion as the languages someone speaks (or not) influence which jobs they can get, which information they can access, and who they can socialise with' (p. 192).

Our data shows that, in Australian universities, inequality in access to LOTE has a socio-spatial dimension. That is to say, students from low SES backgrounds and regional locations have been underrepresented in LOTE courses at university level. Most language enrolments occur within the most selective, metropolitan universities (i.e., Group of Eight). Similarly, students with high ATARs dominate foreign language enrolments, 
and these students are disproportionately likely to be from high SES and metropolitan backgrounds. In what follows, we identify four of the major factors that explain inequality in access to LOTE courses in Australian universities.

\section{Unequal access to LOTE learning areas at a school level}

For students of disadvantaged backgrounds, inequality in access to school curriculum has considerable implications for participation in higher education (Tranter, 2012). For example, participation in language study in higher education is highly influenced by the prior learning experiences of students at school level. In the context of England, Rodeiro (2017) argues that the number of language subjects a student takes at school level has a positive effect on progression to higher education language courses. Likewise, a survey undertaken by the Australian Academy of the Humanities concludes that 'students who have successfully completed year 12 in a given LOTE have the possibility of taking up another language at university level having acquired learning skills that will increase their chances of success' (Nettelbeck et al., 2008, p. 16). Historically, however, curricula in Australian schools have been characterised by hierarchy (Teese, 1998), with disadvantaged schools offering fewer subject choices. Studies that investigate diversity and provision of curriculum in schools in Adelaide (Tranter, 2012) and Perth (Perry \& Southwell, 2014) suggest that socioeconomic composition of schools significantly affects students' choice of subjects. Data from a sample of South Australian secondary schools shows that LOTE learning areas are under-represented in regional and low SES metropolitan schools (Wright, 2010). Discrepancies in provision of learning areas by school type and geographical location in turn suggests differential prior experiences of students in their chosen LOTE subjects at university level.

Our own student survey data shows that students from low SES backgrounds tend to be over-represented in disadvantaged ${ }^{4}$ schools with limited LOTE subject options. Lack of prior foreign language learning experiences might further constrain them from participating in LOTE courses at university level. As Figure 2 shows, low SES schools receive little or no contributions from parents, and have very limited options for LOTE subjects, while high SES schools offer a wide range of foreign language options. In 2015, the Victorian Auditor General's Office (VAGO) released a report entitled Additional School Costs for Families, which evaluated whether Victorian government schools were 'managing parent education costs economically, efficiently and effectively and in accordance with legislation and policies' (VAGO, 2015, p. ix). The report found that between 2009 and 2013 , parent contributions rose by $29 \%$ from $\$ 70$ million to $\$ 310$ million. Schools generate almost as much income themselves (\$626 million in 2013-14) as they receive in cash payments from the Australian Department of Education and Training (DET) (\$771 million in 2013-14) - this figure does not include funding for salaries. Clearly, parent payments have become critical in maintaining government schools. Alarmingly, in 2012, Victoria had the highest average parent contributions per school of all states and territories, with over $\$ 205,000$ per school in parent payments.

Greater financial resources have enabled advantaged schools to employ language teachers and allocate time for LOTE subjects. Independent (private) and Catholic schools are also more likely to provide language offerings than public schools, which further exacerbates socio-economic inequalities (Teese, 2013). As a result, high and medium SES students 


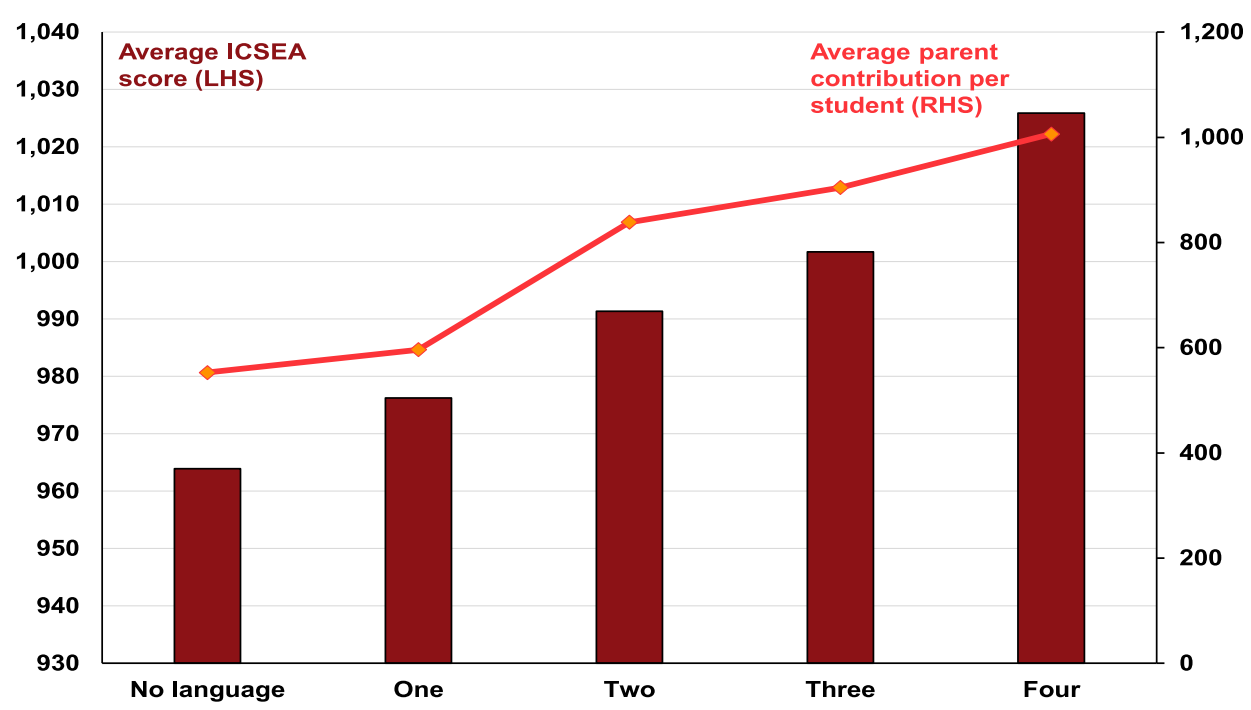

Figure 2. Average ICSEA score and average parent contribution per student, by number of languages provided. Source: Calculated based on data from DET (2014) and My School website (See http://www. myschool.edu.au) for parent contribution data.

are more able to benefit from LOTE learning opportunities in higher education. This is evident in the fact that high SES students account for $46.4 \%$ of the LOTE study cohort, well above their overall university participation rate of $32.1 \%$ and their overall representation within the general population of $25 \%$. By contrast, students from both the medium and low SES backgrounds are underrepresented in comparison to their overall participation within undergraduate university study. The national data set shows that, in $2014,41.6 \%$ of students studying a foreign language were from the medium SES cohort, compared to their overall university participation rate of $49.3 \%$ and their representation of $50 \%$ of the Australian population. The proportion of low SES students studying a foreign language has barely shifted over the past four years and only consisted of $11.7 \%$ of all foreign language enrolments in 2014. This compares to low SES students making up $17.6 \%$ of all undergraduate enrolments and $25 \%$ of the overall Australian population. Based on this data, a high SES student is almost 5 times more likely to be studying a language subject at university as a student from a low SES background. In the context of Australia, the link between socioeconomic background and access to top ranked subjects in the curriculum hierarchy (including foreign languages) is best evidenced by the fact that (high-fee) independent schools are largely dominated by high SES background students and have better modern foreign language subject options than low-fee public schools. For instance, in New South Wales, International Baccalaureate (IB) programs are offered in independent schools, and it is compulsory to study at least one language other than English as part of the program (Board of Studies-NSW, 2013).

\section{Low ATAR results and unequal access to leading LOTE providers}

Compared with their low SES peers, students from high and medium SES backgrounds typically attend better resourced schools, which in turn increases their 


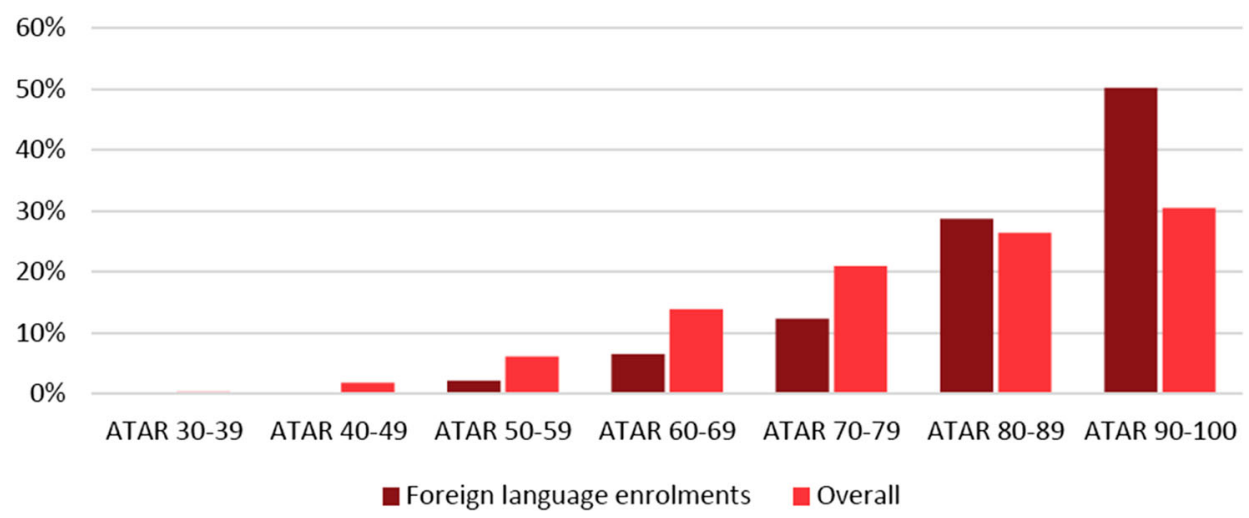

Figure 3. 2014 Foreign language and overall participation rates by ATAR band. Source: Commonwealth Department of Education and Training customised data request (only includes commencing students admitted on the basis of secondary education who were admitted on the basis of their ATAR).

chances of obtaining a more competitive Australian Tertiary Admissions Rank (ATAR). As Teese notes,

The greater the academic training, individual support and organisation, the higher the ATAR. Students attending well-resourced, mainly private schools have an advantage in their access to 'hard options', marks and ATARs. [...] Private school students, on average, have higher ATARs and therefore muscle out the competition [for places in elite universities]. (2015, para.6)

As is shown in Figure 3, 50\% of LOTE students admitted on the basis of their ATAR had achieved an ATAR above 90, which is well above the $30.5 \%$ of students who achieved an ATAR above 90 within the sector generally. Students with an ATAR between 80 and 90 were also slightly over represented within foreign language study, but all ATAR bands below 80 were underrepresented within language study.

Higher ATARs enable students from advantaged backgrounds to dominate the nation's most selective universities (i.e., Group of Eight), which in turn offer a wide range of LOTE courses. For example, in Victoria, 'For the top tenth of undergraduates in 2013, Melbourne and Monash universities together cornered $80 \%$. Of the top $5 \%$ of students, they enrolled 86\%', which includes 'very few of the meritorious poor' (Teese, 2015, para.5). Our data confirms that of all institutional groupings, the Go8 universities have by far the lowest LOTE course participation rate for low SES students. Lack of access to elite universities may mean exclusion from LOTE courses because those universities have high levels of LOTE course provision, and have the highest LOTE participation rate with nearly $10 \%$ of their students participating in foreign language study.

An internal data set from one of the universities that led this project shows that low SES students are more likely to attend public schools, have lower median ATARs compared to their medium and higher SES peers, and are more likely to study a 'strategic' language than an 'academic' language. High SES students who attend independent schools tend to study academic languages with high prestige, such as French. 


\section{Differential prior international learning experiences}

Overseas learning experiences at school level can offer opportunities for developing intercultural competence, including learning languages through immersion (DEECD, 2012). Evidence shows that 'studying a language abroad leads to more oral proficiency gains than studying a language at home' (Potts \& Berquist, 2014, p. 3). In Australia, the policy context is favourable for schools to promote overseas learning experiences for their students. For instance, the Melbourne Declaration on Educational Goals for Young Australians underscores the importance of building students' capabilities to relate and communicate across cultures (MCEETYA, 2008). Similarly, building intercultural understanding is identified as an element of 'general capabilities' in the Australian Curriculum. ${ }^{5}$ However, not all schools are equally positioned to advance those goals. In the context of increased shifts toward private contributions, young people from the privileged middle and upper classes disproportionately benefit from school-based mobility programmes. In low SES schools, limited resources for study abroad programmes mean lack of prior international learning experiences for students. Prior international mobility experiences play vital roles in informing aspirations for foreign language learning. The larger study from which this article is derived shows that students who learn a foreign language at school level often travel overseas and this mobility in turn reinforces their interest in language study and the decision to continue learning foreign language at university level, which in turn further strengthens their possibilities for mobility (Harvey et al., 2016).

\section{Limited LOTE course options in regional university campuses}

Compared to their metropolitan peers, students from rural/regional areas have low participation and attrition rates in LOTE (Lo Bianco \& Slaughter, 2009). Our study also found that regional universities were less likely to offer a wide range of LOTE options. In some cases, regional universities offered no foreign language options at all (Dunne \& Pavlyshyn, 2012). Our data confirms that, like low SES students, regional background students were underrepresented both in comparison to their participation rates within undergraduate study nationally, and the overall demographics of the Australian population. In 2014, only $14.1 \%$ of students studying a foreign language were from a regional background, compared to the overall national participation rate of $20.6 \%$ in the same year and the $30.8 \%$ of the Australian population who live in regional or remote areas (RAI, 2015).

Data from the Victorian secondary school sector confirms that language provision is correlated with socio-economic and regional status. Figure 4 shows that over $70 \%$ of the schools that did not provide any foreign language study were from regional areas, while fewer than $10 \%$ of those schools which provided access to four languages were from regional areas.

Our data reveals that universities with higher levels of students from recognised equity groups have lower levels of language provision. When measured as a ratio between foreign language and overall enrolments, RUN institutions reported the largest gap, followed by IRU institutions. Go8 and unaligned institutions reported the lowest gap between language study and overall low SES participation rates. This suggests that, once admitted, low SES students are represented equally within foreign language study. On the other hand, the poor performance of RUN institutions relative to their general low SES 


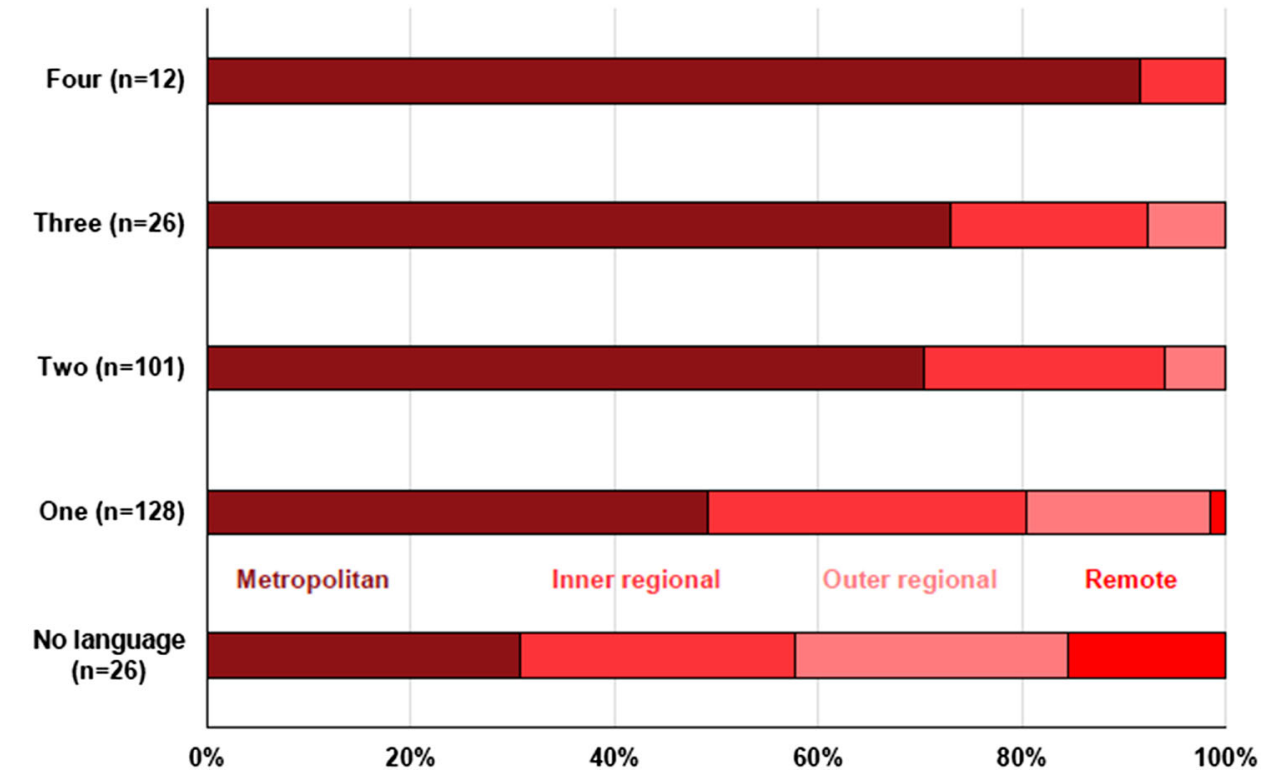

Figure 4. Remoteness of school and number of languages provided. Source: Customised data based on Victorian Department of Education and Training (2015).

participation could be a sign of structural issues relating to a lack of foreign language study options in higher education and possibly within secondary school. A data set from one of the two universities that led this project shows that low SES students have lower median ATAR compared to their medium and higher SES peers.

\section{Beyond the instrumentalist view of LOTE}

Despite its broad socio-economic and cultural benefits, more often than not the foreign language education debate is framed by a human capital view of education and training, which sees spending on education as an investment with an economic return (Becker, 1962). A review of language education policies and practices in different national contexts shows that the importance of foreign language education is typically framed in terms of global competitiveness and/or national security. For example, the 'Languages for Jobs' initiative in the U.S. underscores that the global competitiveness of a nation depends partly on its ability to produce 'global-ready' graduates who, among other things, are competent in foreign languages (Wiley, Moore, \& Fee, 2012). The initiative recognises a 'foreign language education deficit' in the U.S. education system, and highlights the economic implications of the deficiency: 'It is an old adage that you can buy in any language, but you must sell in the language of your customer' (Wiley et al., 2012, para.2). The assumption here is that proficiency in foreign languages provides a special ability to understand other cultures and to do business in transnational contexts. In 2010, then U.S. Education Secretary, Arne Duncan, stressed that:

To prosper economically and to improve relations with other countries, Americans need to read, speak and understand other languages. It's absolutely essential for the citizens of the 
United States to become fluent in other languages and schools, colleges and universities must include producing bilingual students as a central part of their mission. (Duncan, 2010, para.12-13)

Within this human capital paradigm, the curriculum is moulded by the needs of the labour market.

In Australia, the study of LOTE is closely associated with economic agendas and the recent focus has been on making the nation 'Asia-literate' or 'Asia-capable' (Lo Bianco, 2016). Not only does the human capital framing economise education, it also personalises educational spending, thereby shifting the responsibility from the state to the individual. It is possible that this narrow framing of language study might have contributed to the decline of participation in LOTE courses in the nation's universities. The number of foreign languages offered in Australian universities declined from 66 in 1997 to 29 in 2007 (Group of Eight, 2007). ${ }^{6}$ Relative to students of high SES and metropolitan backgrounds, low SES and non-urban students are traditionally underrepresented in higher education. Most often, the latter groups live in areas with low levels of language education provision. Hence, they are less likely to have studied a language in primary school and secondary school. As a result, regional students are often not positioned to 'compete in a globalised economy on the same footing as their metropolitan counterparts' (Dunne \& Pavlyshyn, 2012, pp. 12-13).

Transforming structural factors of inequality in access to LOTE requires an expansive view of the value of language study. As a public good, language is instrumental in fostering meaningful interactions and structuring social cooperation (Taylor, 2014). Learning to read and write in additional languages makes people better citizens who can contribute to the good of society. In the context of a multicultural society such as Australia, competence in LOTE enhances individuals' ability to engage in inter-group interactions and dialogues. In the words of Lo Bianco and Slaughter (2009): 'Bilingualism can foster more reflective and imaginative dispositions in citizens, and the principles of democratic discourse, participation and opportunity which Australia proclaims also find resonance with language study' (p. 64). Likewise, Nixon (2011) argues, 'human beings develop relationally through social, civic and cosmopolitan interconnectivities' (p. 65). Competence in LOTE is a catalyst for effective interconnection in multicultural communities. Linguistically competent people are able to explore different cultural worlds and engage in cross-cultural communication.

\section{Conclusion}

Multilingualism is an increasingly important precondition for individuals to benefit equally from globalisation opportunities such as transnational mobility and employment. Beginning from this understanding, we explored access to LOTE study in Australian universities in relation to socio-economic status and geographical location. Students in disadvantaged schools tend to have unequal access to LOTE learning areas, which in turn influences their dispositions to learn LOTE at university level. In addition, mainly due to low tertiary admission rankings, they are under-represented in the nation's most selective universities, which offer a wider range of LOTE courses compared to other university groupings. Also, as a result of lack of resources, students from low SES and regional 
backgrounds tend to have limited prior international learning experiences that might inform their aspirations for intercultural competence and learning LOTE. Finally, as regional university campuses offer few or no LOTE course options, regional students are disadvantaged in relation to the opportunities of LOTE in the Australian university system. In other words, whether or not low SES and regional background students study LOTE at a university level is mediated by a range of factors, including the level of language subject options they had at a school level, ATAR scores and access to elite universities, prior international learning experiences, and LOTE course options in regional campuses.

We have argued in this article that the study of languages other than English is becoming central to university globalisation strategies. Despite the development of these strategies, however, students from regional and low SES backgrounds remain dramatically under-represented in foreign language enrolments. This article has highlighted several causal factors of this under-representation, particularly focusing on the pipeline from school to university. The hierarchy of the school curriculum, the stratified nature of the Australian school sector, and the particular concentration of language resources in welloff metropolitan schools all contribute to unequal patterns of language participation that are formed within the school sector and are subsequently translated to the higher education sector. Improving student equity within university globalisation strategies will depend partly on acknowledging, and then addressing, this educational pipeline of privilege. The four factors of inequalities highlighted in this article can be seen as further evidence of how education systems reproduce advantage and disadvantage in society.

Language learning has greater benefits than those calculated in a narrow human capital frame and thus governments have a responsibility to ensure equitable access to them as a public good. Australia is a multilingual and multicultural society. One in four people living in Australia is born overseas (ABS, 2017b), and one in five people speak a language other than English at home (ABS, 2017a). Hence, beyond a utilitarian calculation for learning languages, there is a need for recognising non-economic and societal benefits of LOTE. Multilingual competence should be seen as a national asset for its broad benefits; and widening access to languages other than English should be guided by socio-cultural rationales, not just economic ones. Hence, at the centre of our argument is the view that LOTE is a public good and its provision should be a public responsibility. Universities, schools and others need to explicitly address the disparities of LOTE enrolments, which is exacerbating a broader inequity in relation to the educational goal of creating global citizens.

\section{Notes}

1. uCube can be found at http://highereducationstatistics.education.gov.au/.

2. See http://nzcurriculum.tki.org.nz/The-New-Zealand-Curriculum/Learning-areas/Learninglanguages/Why-study-a-language.

3. At the end of Key Stage 4 (age 16, or Year 11), students take school leaving examinations called General Certificate of Secondary Education (GCSE). After completing GCSEs, based on their scores, students can take A Level (Advanced Level) examinations (Key Stage 5). An A level qualification is one of the main routes into HE, and consists of AS (Advanced Subsidiary) and A2 (Advanced Year Two) level courses and examinations, which are taken in Year 12 and Year 13 respectively. 
4. Here we use the advantaged/disadvantaged school category following Australian Curriculum, Assessment and Reporting Authority's Index of Community Socio-Educational Advantage (ICSEA), which uses parental occupation and education, proportion of indigenous students and geographical location.

5. See http://www.australiancurriculum.edu.au/generalcapabilities/overview/introduction.

6. In recent years, the trend of decline in foreign language courses in Australian universities seems to be changing. At the time of writing (April 2018), the University Languages Portal Australia (ULPA) lists over 40 foreign languages offered at beginner-level in Australian universities. See https://www.ulpa.edu.au/what-languages-can-i-study/.

\section{Acknowledgements}

We acknowledge the contributions of other members of the research team who worked on the project from which this paper is derived. These are Dr Aspa Baroutsis, Beni Cakitaki, Jenna Tellefson, Michael Luckman, Giovanna Szalkowicz and Matt Brett. We are also grateful to the two anonymous reviewers for their thoughtful comments.

\section{Disclosure statement}

No potential conflict of interest was reported by the authors.

\section{Funding}

This work was supported by the Australian Government Department of Education and Training (DET).

\section{ORCID}

Tebeje Molla (D) http://orcid.org/0000-0002-6848-3091

Andrew Harvey (i) http://orcid.org/0000-0002-7988-2469

Sam Sellar (D) https://orcid.org/0000-0002-2840-5021

\section{References}

ABS (Australian Bureau of Statistics). (2017a). 2016 census: Multicultural. Retrieved from http:// www.abs.gov.au/ausstats/abs@.nsf/lookup/Media\%20Release3

ABS (Australian Bureau of Statistics). (2017b). Snapshot of Australia: 2016 census data summary. Retrieved October 21, 2017, from http://www.abs.gov.au/ausstats/abs@.nsf/mf/2071.0

Anderson, K. (2013). Languages, the Asian Century White Paper and three provocations for the committed from a pragmatic humanist three myths obstructing our success. LCNAU 2013 proceedings, 19-38.

Asia New Zealand Foundation. (2015). New Zealanders' perceptions of Asia and Asian peoples 2014 annual survey. Retrieved from http://asianz.org.nz/reports/wp-content/uploads/2015/02/ ANZF1046-Perceptions-of-Asia-Report2.pdf

AUCC (Association of Universities and Colleges of Canada). (2009). Internationalization of the curriculum: A practical guide to support Canadian universities' efforts. Retrieved from http://www. univcan.ca/wp-content/uploads/2011/07/curriculum-primer-2009-03-31-e.pdf

AUCC [Association of Universities and Colleges of Canada]. (2014). Canada's universities in the world: AUCC internationalization survey 2014. Ottawa: Author.

Becker, G. S. (1962). Investment in human capital: A theoretical analysis. The Journal of Political Economy, 70(5), 9-49. 
Board, K., \& Tinsley, T. (2015). Modern foreign languages in secondary schools in Wales. Retrieved on September 17, 2017, from https://wales.britishcouncil.org/sites/default/files/language_trends_ wales_report_english.pdf

Board of Studies-NSW. (2013). Learning through languages: Review of languages education in NSW. Sydney: Author.

Bowden, J. A., Starrs, C. D., \& Quinn, T. J. (1989). Modern language teaching in Australian universities. Higher Education Research \& Development, 8(2), 129-146.

Cambridge Assessment. (2009). Retrieved from http://www.cambridgeassessment.org.uk/Images/ 109964-as-and-a-level-choice-factsheet-10.pdf

Charbonneau, L. (2008, August 5). The rise of the monoglots. University Affairs. Retrieved from http://www.universityaffairs.ca/features/feature-article/the-rise-of-the-monoglots/

Creswell, J. W. (2014). Research design: Qualitative, quantitative and mixed methods approaches (4th ed.). Thousand Oaks: Sage Publications, Inc.

DEECD (Department of Education and Early Childhood Development, Victoria). (2012). Overseas learning experiences for students: A resource for schools. Melbourne: Author.

della Chiesa, B. (2010). Wanted: Tesseract. One hypothesis on languages, cultures, and ethics for mind, brain, and education. Mind, Brain, and Education, 4(3), 135-148.

DET (Department of Education and Training, State Government, Victoria). (2014). Languages provision in Victorian government schools. Melbourne: Author.

Duncan, A. (2010). Education and the language gap: Secretary Arne Duncan's remarks at the foreign language summit. Retrieved July 22, 2015, from http://www.ed.gov/news/speeches/educationand-language-gap-secretary-arne-duncans-remarks-foreign-language-summit

Dunch, R. (2012, December 12). Canada is facing a China knowledge deficit. University Affairs. Retrieved from http://www.universityaffairs.ca/opinion/in-my-opinion/canada-is-facing-achina-knowledge-deficit/

Dunne, K., \& Pavlyshyn, M. (2012). Swings \& roundabouts: Changes in university language offerings 2005-2011.

Goldberg, D., Looney, D., \& Lusin, N. (2015). Enrollments in languages other than English in United States Institutions of higher education, fall 2013. MLA. Retrieved from http://www. mla.org/pdf/2013_enrollment_survey.pdf

Group of Eight. (2007). Languages in crisis: A rescue plan for Australia. Retrieved from https://go8. edu.au/sites/default/files/agreements/go8-languages-in-crisis-discussion-paper.pdf

Habel, C. (2012). 'I can do it, and how!' Student experience in access and equity pathways to higher education. Higher Education Research \& Development, 31(6), 811-825.

Harvey, A., Sellar, S., Molla, T., Baroutsis, A., Cakitaki, B., Tellefson, J., ... Brett, M. (2016). Globalization opportunities for low socio-economic status and regional students. Report for the Australian Government Department of Education and Training, Melbourne, La Trobe University.

Hunter, W. (2004). Knowledge, skills, attitudes, and experiences necessary to become globally competent (UMI dissertation services).

Kinoshita, Y., \& Zhang, Y. (2013). Why do we teach languages at universities? Re-conceptualization of foreign language education. LCNAU 2013 proceedings, 87-99.

Koshy, P. (2014). Student equity performance in Australian higher education: 2007 to 2012. National Centre for Student Equity in Higher Education (NCSEHE). Perth: Curtin University.

Lo Bianco, J. (2016). Multicultural education in the Australian context: An historical overview. In J. Lo Bianco, \& A. Bal (Eds.), Learning from difference: Comparative accounts of multicultural education (pp. 15-33). Cham: Springer.

Lo Bianco, J., \& Slaughter, Y. (2009). Second languages and Australian schooling. Australian Education Review, 54, 1-73.

MCEETYA [The Ministerial Council on Education, Employment, Training and Youth Affairs]. (2008). Melbourne declaration on educational goals for young Australians. Retrieved on August 23, 2015, from http://www.curriculum.edu.au/verve/_resources/National_Declaration_ on_the_Educational_Goals_for_Young_Australians.pdf 
McNamee, P. J., \& Maxwell, G. S. (1993). Access and equity: A case analysis of local implementation under the Higher Education Equity Programme. Higher Education Research \& Development, 12 (2), 207-223.

Nettelbeck, C., Byron, J., Clyne, M., Hajek, Levy, M., Lo Bianco, J., \& Wigglesworth, G. (2008). Beginners' LOTE (Languages Other than English) in Australian universities: An audit survey and analysis. Report to the Council of the Australian Academy of the Humanities. Canberra: Australian Academy of the Humanities.

Nixon, J. (2011). Higher education and the public good: Imagining the university. London: Continuum.

O'Shea, S., Lysaght, P., Roberts, J., \& Harwood, V. (2016). Shifting the blame in higher education social inclusion and deficit discourses. Higher Education Research \& Development, 35(2), 322-336.

Perry, L., \& Southwell, L. (2014). Access to academic curriculum in Australian secondary schools: A case study of a highly marketised education system. Journal of Education Policy, 29(4), 467-485.

Piller, I. (2014). Editorial: Linguistic diversity and social inclusion in Australia. Australian Review of Applied Linguistics, 37(3), 190-197.

Potts, D., \& Berquist, B. (2014). Researching outcomes of international learning mobility: Taking the next steps. Canberra: IEAA.

RAI (Regional Australia Institute). (2015). Population dynamics in regional Australia. Retrieved on October 23, 2017, from http://www.regionalaustralia.org.au/wp-content/uploads/2015/01/ FINAL-Population-Dynamics-in-Regional-Australia.pdf

Reid, J., Barker, J., \& Murphy, K. (1995). Quality and equity in Australian universities: Contradictions and challenges. Higher Education Research \& Development, 14(2), 233-243.

Rodeiro, C. V. (2017). The study of foreign languages in England: Uptake in secondary school and progression to higher education. Language, Culture and Curriculum, 30(3), 231-249.

Scholte, J. A. (2005). Globalization: A critical introduction (2nd ed.). New York: Palgrave Macmillan.

Scottish Government. (2012). Language learning in Scotland A 1+2 approach: Scottish government languages working group: Report and recommendations. Retrieved from http://www.gov.scot/ Resource/0039/00393435.pdf

Taylor, I. (2014). Language as a global public good. Res Publica, 20(4), 377-394.

Teese, R. (1998). Curriculum hierarchy, private schooling, and the segmentation of Australian secondary education, 1947-1985. British Journal of Sociology of Education, 19(3), 401-417.

Teese, R. (2013). Academic success and social power: Examinations and inequality. Melbourne: Australian Scholarly Publishing Pty. Ltd.

Teese, R. (2015, December 21). How our elite unis 'game' the VCE and ATAR. The Age.

Thomas, G. (2014). Closing the policy-practice gap for low-SES students in higher education: The pedagogical challenge. Higher Education Research \& Development, 33(4), 807-820.

Tinsley, T. (2013). Languages: The state of the nation: Demand and supply of language skills. London: British Academy.

Tinsley, T., \& Han, Y. (2012). Language learning in secondary schools in England. Findings from the 2011 language trends survey. CfBT Education Trust. Retrieved from http://cdn.cfbt.com/ / media/cfbtcorporate/files/research/2012/r-language-learning-in-secondary-schools-in-englandlanguage-trends-2012.pdf

Tranter, D. (2012). Unequal schooling: How the school curriculum keeps students from low socioeconomic backgrounds out of university. International Journal of Inclusive Education, 16(9), 901-916.

UNESCO (United Nations Educational, Scientific and Cultural Organization). (1995). Declaration and integrated framework of action on education for peace, human rights and democracy. Paris: Author.

VAGO (Victorian Auditor General's Office). (2015). Additional school costs for families. Melbourne: Victorian Government Printer.

Victorian Department of Education and Training. (2015). Languages provision in Victorian government schools, 2014. Melbourne: Author. 
Wiley, T. G., Moore, S. C., \& Fee, M. S. (2012). A 'languages for jobs' initiative. Policy Innovation Memorandum No. 24. Retrieved from http://www.cfr.org/united-states/languages-jobsinitiative/p28396

Willems, J. (2010). The equity raw-score matrix - a multi-dimensional indicator of potential disadvantage in higher education. Higher Education Research \& Development, 29(6), 603-621.

Wright, S. (2010). Course diversity within South Australian secondary schools as a factor of successful transition and retention within Australian universities. The International Journal of the First Year in Higher Education, 1(1), 21-30. 